\title{
Caroço de açaí triturado in natura no desenvolvimento de mudas de Paricá (Schizolobium parahyba var. amazonicum (Huber ex Ducke) \\ Barneby)
}

Na cidade de Belém há ocorrência da alta produção de resíduos oriundos do beneficiamento do caroço de açaí, em razão deste fruto ser um artigo que estimula o setor econômico da capital. No entanto, caso não seja disposto adequadamente, pode causar problemas ambientais como obstrução de canais de drenagem, ocasionando os alagamentos, poluição de vias, entre outras externalidades. Somado a isso, tem-se a Política Nacional de Resíduos Sólidos (PNRS), instituída pela Lei no 12.305/2010 que impulsiona a elaboração de aparatos com intuito de reuso de resíduos sólidos gerados por diversas atividades. Objetivou-se com este trabalho avaliar semanalmente o desenvolvimento de mudas de Paricá (Shizolobium amazonicum) em Latossolo Amarelo de textura média misturado em diferentes proporç̃ões de caroço de açaí triturado por 60 dias, através de análises dos parâmetros morfológicos da planta. Os experimentos foram dispostos em casa de vegetação com delineamento inteiramente casualizado, totalizando dez tratamentos e quatro repetições. As variáveis analisadas foram altura da parte aérea (APA), dispostos em casa de vegetação com delineamento inteiramente casualizado, totalizando dez tratamentos e quatro repetições. As variáveis analisadas foram altura da parte aérea (APA),
diâmetro do coleto (DC), matéria seca da parte aérea (MSPA), matéria seca de raiz (MSR) e área foliar (AF). Os dados foram tratados e submetidos à análise de variância (ANOVA) (p<0,05) e comparados pelo teste $t$, por meio do software ASSISTAT Versão 7.7, seguidos Correlação de Pearson efetuada no software Past 3.26. 0 caroço de açaí triturado apresentou resultados satisfatórios tendo como principal tratamento o T8 com valores de altura, diâmetro do coleto MSPA, MSR, MST e área foliar de $24,07 \mathrm{~cm}^{3} 3,95 \mathrm{~mm}, 0,76 \mathrm{~g}, 2,32 \mathrm{~g}, 3,09 \mathrm{~g}$ e $111,25 \mathrm{~cm}^{2}$ respectivamente. Logo, o açaí triturado pode auxiliar no desenvolvimento de mudas em áreas degradadas, o que significa uma nova destinação ao resíduo.

Palavras-chave: Açaí; Paricá; Resíduos Orgânicos; Recuperação de Áreas Degradadas; Espécie Florestal.

\section{Cruncehd core of açai seed in natura in the development of Paricá seedlings (Schizolobium parahyba var. amazonicum (Huber ex Ducke) Barneby)}

In the city of Belém there is a high production of residues from the processing of the açai core, because this fruit is an article that stimulates the capital's economic sector. However, if not properly disposed, it can cause environmental problems such as obstruction of drainage channels, causing flooding, pollution of roads, among other externalities. In addition, there is the National Solid Waste Policy (NSWP/PNRS), instituted by Law No. 12,305/2010, which promotes the elaboration of devices with the intention of reusing solid waste generated by various activities. The objective of this work was to weekly evaluate the development of Paricá seedlings (Shizolobium amazonicum) in a medium texture Yellow Latosol mixed in different proportions of açai stone ground for 60 days, through analyzes of the plant's morphological parameters. The experiments were arranged in a greenhouse with a completely randomized design, totaling ten treatments and four replications. The variables analyzed were shoot height (APA), stem diameter (DC), shoot dry matter (MSPA), root dry matter (MSR) and leaf area (AF). The data were treated and submitted to analysis of variance (ANOVA) $(p<0.05)$ and compared using the $t$ test, using the ASSISTAT Version 7.7 software, followed by Pearson's correlation performed in the treated and submitted to analysis of variance (ANOVA) $(p<0.05)$ and compared using the $t$ test, using the ASSISTAT Version 7.7 software, followed by Pearson's correlation performed in the
Past 3.26 software. The crushed açai seed showed satisfactory results, having T8 as the main treatment, with values for height, stem diameter MSPA, MSR, MST and leaf area of $24.07 \mathrm{~cm}$, $3.95 \mathrm{~mm}, 0.76 \mathrm{~g}, 2.32 \mathrm{~g}, 3.09 \mathrm{~g}$ and $111.25 \mathrm{~cm}^{2}$, respectively. Therefore, crushed açai can assist in the development of seedlings in degraded areas, which means a new destination for the waste.

Keywords: Açaí; Paricá; Organic waste; Recovery of Degraded Areas; Forest Species.

Topic: Ciências Florestais

Reviewed anonymously in the process of blind peer
Received: 03/02/2021

Approved: 27/02/2021
Leandro Marques Torres (D)

Universidade Federal Rural da Amazônia, Brasil

http://lattes.cnpq.br/2678860527695504

http://orcid.org/0000-0001-5976-6340

leandrotorres15@yahoo.com.br

Lorena Fernanda Araújo Soares (iD)

Universidade Federal do Pará, Brasil

http://lattes.cnpq.br/3424684009064743

http://orcid.org/0000-0002-3757-2155

lorenaasoaares@gmail.com

\section{Sarah Dias Azevedo (iD}

Universidade Federal Rural da Amazônia, Brasil

http://lattes.cnpq.br/7721203184014688

http://orcid.org/0000-0002-5105-1794

saaahazevedo@gmail.com

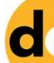

DOI: 10.6008/CBPC2179-6858.2021.002.0008
Suzana Romeiro Araújo (D)

Universidade Federal Rural da Amazônia, Brasil

http://lattes.cnpq.br/7289473902924417

http://orcid.org/0000-0002-3569-8440

suzanaromeiro@yahoo.com.br

Regilene Angélica da Silva Souza (1)

Universidade Federal Rural da Amazônia, Brasil

http://lattes.cnpq.br/0574812911676652

http://orcid.org/0000-0003-2413-6298

regilenesouza@yahoo.com.br
Referencing this:

TORRES, L. M.; SOARES, L. F. A.; ARAÚJO, S. R.; SOUZA, R. A. S.. Caroço de açaí triturado in natura no desenvolvimento de mudas de Paricá (Schizolobium parahyba var. amazonicum (Huber ex Ducke) Barneby) Revista Ibero Americana de Ciências Ambientais, v.12, n.2, p.68-76, 2021. DOI: http://doi.org/10.6008/CBPC2179-6858.2021.002.0008 


\section{INTRODUÇÃO}

Os resquícios agroflorestais fazem parte central da composição de biomassa no País e quase 600 milhões de toneladas provém de diversos meios de culturas como a da soja, trigo, cana-de-açúcar, arroz, milho, entre outros (FERREIRA-LEITAO et al., 2010; BARROS, 2017).

Analisando as dificuldades socioambientais no país referentes à disposição de resíduos, tem-se a Política Nacional de Resíduos Sólidos (PNRS), com diretrizes, normativas, instrumentos e princípios. De acordo com a Lei $12.305 / 10$, os resíduos de origem animal e da agroindústria tem como classificação agrossilvopastoris, onde são incumbidos os insumos (BRASIL, 2010).

Portanto, técnicas e metodologias vêm ganhando destaque e atenção para novos fins aos resíduos agrossilvopastoris, uma delas seria o uso na fabricação de substratos à geminação de espécies vegetais, tal qual servir de auxílio na restauração de regiões degradadas; mitigando a dispersão destes no meio ambiente (TEIXEIRA et al., 2004; ERLACHER et al., 2016).

O caroço de açaí pode ser moldado de diferentes formas, como na sua trituração tornando o material menos volumoso e simples de manejar na implantação ao substrato (FElO et al., 2014)

Com a ocorrência da perda de material orgânico e nutrientes essenciais ao virarem resíduos, percebe-se a necessidade de conceder uma destinação adequada a estes a fim de mitigar impactos ambientais. Assim, é imprescindível uma destinação correta a estes insumos com intuito de atenuar degradação dos recursos hídricos, solo incômodos sociais (ROSA et al., 2011; BICAS, 2016).

Logo, objetivou-se avaliar o desenvolvimento de mudas de Paricá (Shizolobium amazonicum) em Latossolo Amarelo de textura média tratado com açaí triturado in natura, através de análises morfológicas da parte aérea da planta e atributos químicos do solo. A espécie florestal fora escolhida pois possui características de ágil crescimento e utilidade em áreas degradadas. Com a utilização dos substratos propostos, visa-se a atenuação de custos com insumos, para uma espécie de rápido crescimento e de viabilidade econômica. Logo, espera-se obter bons resultados do açaí triturado no desenvolvimento de mudas de Paricá (Shizolobium amazonicum) assim como o aproveitamento dos resíduos em substratos.

\section{MATERIAIS E MÉTODOS}

\section{Caracterização do experimento}

Este estudo foi desenvolvido na Casa de Vegetação do Instituto de Ciências Agrárias - ICA pertencente à Universidade Federal Rural da Amazônia (UFRA), localizada na cidade de Belém/PA, nas coordenadas $01^{\circ} 27^{\prime} 18,29^{\prime \prime}$ S e $48^{\circ} 26^{\prime} 19,01^{\prime \prime} O$. O solo utilizado no ensaio foi o Latossolo Amarelo de textura média coletado no campus da UFRA, Belém, nas coordenadas $01^{\circ} 27^{\prime} 03,46^{\prime \prime} \mathrm{S}$ e $48^{\circ} 26^{\prime} 27,81^{\prime \prime} \mathrm{O}$.

Após coletado, o solo foi seco ao ar por 7 dias, destorroado e passado em peneira de malha $10 \mathrm{~mm}$ e alocado com as devidas proporções, em tubetes de $280 \mathrm{dm}^{3}$. 


\section{Descrição dos tratamentos}

O experimento foi avaliado num período de 60 dias, com diferentes proporções de solo e de caroço de açaí triturado. Este seguiu a metodologia de Carvalho et al. (2017), com avaliações semanais de propriedades morfológicas da planta e, tendo como base o tempo e o tamanho apropriado para o plantio das mudas em campo, entre $20 \mathrm{~cm}$ a $35 \mathrm{~cm}$ de altura.

O experimento contou com dez tratamentos e quatro repetições, totalizando 40 tubetes de $280 \mathrm{dm}^{3}$ instalados em casa de vegetação do Instituto de Ciências Agrárias - ICA, com delineamento inteiramente casualizado: T1 - 100\% de solo, sem adubação química, sem calagem e, sem adição de açaí triturado; T2 $100 \%$ de solo, com adubação química conforme a necessidade da cultura e sem calagem e sem adição de açaí triturado; T3 - 100\% solo com calagem, sem adubação e sem adição do açaí triturado; T4 - 50\% de solo, 50\% de açaí triturado, sem adubação química, e sem calagem; T5 - 50\% de solo, 50\% de açaí triturado, com adubação química conforme a necessidade da cultura, e sem calagem; T6 - 50\% de solo, 50\% de açaí triturado, sem adubação química conforme a necessidade da cultura, e com calagem; T7 - 25\% de solo, 75\% de açaí triturado, sem adubação química e sem calagem; T8 - 25\% de solo, $75 \%$ de açaí triturado, com adubação química e sem calagem; T9 - 25\% de solo, $75 \%$ de açaí triturado, sem adubação química e com calagem; T10 - 100\% açaí triturado.

Nos tratamentos $(T 3, T 6, T 9)$ que receberam calcário, a calagem foi realizada 20 dias antes da semeadura com intuito de elevar a saturação por bases do solo a $70 \%$. Neste período de incubação todos os tratamentos recebiam irrigação diariamente, em dose única (SATO, 2018). Passando-se uma semana após o transplantio, foi realizada adubação por cobertura de $\mathrm{N}, \mathrm{K}, \mathrm{S}, \mathrm{Mg}$, e Ca com adição de $2 \mathrm{~mL}$ de solução nutritiva nos tubetes selecionados previamente (T2, T5 e T8), contendo $1 \mathrm{~mL} / \mathrm{L}$ de $\mathrm{KH}_{2} \mathrm{SO}_{4} \mathrm{M}, 5 \mathrm{~mL} / \mathrm{L}$ de $\mathrm{KNO}_{3}$ $\mathrm{M}, 5 \mathrm{~mL} / \mathrm{L}$ de $\mathrm{Ca}\left(\mathrm{NO}_{3}\right)_{2} \mathrm{M}, 2 \mathrm{~mL} / \mathrm{L}$ de $\mathrm{MgSO}_{4} \mathrm{M}$ e $1 \mathrm{~mL} / \mathrm{L}$ de Fe-EDTA.

\section{Obtenção das mudas de Paricá}

Utilizaram-se sementes da espécie Paricá (Shizolobium parahyba var. amazonicum (Huber ex Ducke) Barneby), devido ao seu rápido crescimento, bom desenvolvimento em temperaturas relativamente elevadas e por ser característica da Região Amazônica (SOUSA, 2015). Inicialmente, fez-se necessário uma seleção manual de 60 sementes, nas quais as mais bem padronizadas em relação a cor, tamanho e espessura, foram selecionadas.

As sementes foram selecionadas de acordo com essas características no intuito de evitar possíveis entraves e diferenciação de resultados (SHIMIZU et al., 2011). A seleção de sementes é essencial tendo em vista que a uniformidade por comprimento resulta num acréscimo de melhores condições no momento da semeadura (KRZYZANOWSKI et al., 1991; PÁDUA et al., 2010).

Foram efetuadas escarificações a fim de acelerar o processo de germinação das mudas quando fossem alocadas em substrato. A ação de escarificação ocorreu de modo manual por atrito com auxílio de uma lixa madeira, na intenção de acelerar a germinação. $O$ ato foi realizado na parte contrária ao eixo 
embrionário do elemento. Em razão das sementes deterem dormência tegumentar, tornou-se fundamental a utilização da escarificação para ruptura da mesma (FRIGOTTO et al., 2015).

Já escarificadas, receberam embebedamento por água destilada num período de $24 \mathrm{~h}$, com o intuito de mantê-las bem hidratadas para o semeio (SHIMIZU et al., 2011; NEVES et al., 2010). Passado este tempo, as sementes foram semeadas em um recipiente contendo vermiculita e casca de arroz na proporção 1:1 para que permitisse o desenvolvimento até uma estatura adequada para efetuar o transplante de local.

\section{Obtenção do caroço de açaí}

O resíduo do caroço de açaí foi obtido através do Projeto de Pesquisa 'Resíduos agroflorestais e urbanos na produção de mudas de espécies nativas usadas na recuperação de áreas impactadas no Estado do Pará' da Universidade Federal Rural da Amazônia, coordenado pela Professora Regilene A. Souza.

Este produto teve sua confecção seguindo o beneficiamento do fruto (despolpamento para obtenção do suco) em localidades de zona econômica na Região Metropolitana da capital do Estado. Então, fez-se processos de trituramento com uso de um triturador orgânico e o próprio peneiramento do caroço a fim de retirar todos os resíduos com maior granulometria. Para o experimento 2, teve-se a quantidade estimada de $2 \mathrm{~kg}$ para incorporação nos tubetes.

\section{Análises morfológicas e massa seca das plantas}

Após 7 dias da semeadura, iniciaram-se as seguintes análises morfológicas: altura da parte aérea (APA), expressa em cm; diâmetro do coleto (DC), expresso em $\mathrm{mm}$ e número de pares de folhas. Repetindo as mesmas análises até o fim do experimento com intervalos de 7 dias.

Ao término do experimento, as mudas de Paricá foram extraídas dos tubetes para realização das seguintes análises: área foliar, expressa em cm2, massa seca da parte aérea (MSPA), expressa em g; massa seca do sistema radicular (MSR), expressa em g e; massa seca total (MST), expressa em g e área foliar.

Para as medições da APA e DC, foram utilizados uma régua e um paquímetro, com precisão de 0,01 $\mathrm{mm}$. Após isso, com o auxílio de uma tesoura, as mudas foram separadas em parte aérea e sistema radicular. Já separadas as partes, e após limpeza do sistema radicular em água corrente, foi realizada a mensuração da área foliar em $\mathrm{cm}^{2}$ por meio do medidor de área da marca LI-3100.

No passo seguinte, as partes aéreas foram submetidas à uma estufa de circulação forçada, a 70 ㄷ C até atingirem peso constante. Com o uso de uma balança analítica, com precisão de três casas decimais, após o esfriamento das amostras, determinaram-se os pesos de MSPA e MSR. A MST foi obtida a partir da soma das massas secas da parte aérea e do sistema radicular, muda por muda. Determinados os resultados das análises supracitadas, os valores foram submetidos à equação abaixo, a fim de se obter o Índice de Qualidade de Dickson (IQD) (DICKSON et al., 1960).

$$
I Q D \frac{M S T_{(g)}}{\frac{H_{(\mathrm{cm})}}{D C_{(m m)}}+\frac{M S P A_{(g)}}{M S R_{(g)}}}(\text { eq.1) }
$$




\section{Análises estatísticas}

Os dados foram submetidos à análise de variância a 5\% de probabilidade, sendo todas as médias atreladas pelo test T Student. Os valores foram incorporados no software ASSISTAT Versão 7.7. Por fim, realizou-se a Correlação de Pearson com auxílio do Past 3.26.

\section{RESULTADOS E DISCUSSÃO}

Os tratamentos T5 e T6 não desenvolveram nenhuma muda após a semana do transplantio nos tubetes, sendo estes não consideráveis para as medições e estatísticas, pois avaliam-se os tratamentos como falhos. A justificativa para este acontecimento pode ser ao fato do experimento estar contido na casa de vegetação e ter contraído alguma praga por espécies vizinhas (PADUA et al., 2010).

Houve variação significativa da altura da planta entre todos tratamentos avaliados após os 7 dias de transplantio e nas semanas seguintes (Tabela 1). O T3 que contém 100\% de solo com a adição de calagem, apresentou a maior média de altura de planta, com 25,37 cm ao final do experimento e, o T4 que contém $50 \%$ de caroço de açaí triturado e 50\% solo apresentou o menor valor, com 15,6 cm.

Vale destacar que T10, caracterizado por possuir 100\% de açaí triturado, apresentou resultado semelhante a T1 no término dos 60 dias, indicando uma possível alternativa ao resíduo. Tanto o T1 quanto T10 tiveram similaridade pois ambos não receberam métodos corretivos para o desenvolvimento das mudas, justificando essa relação (Tabela 1).

Verifica-se que no final do período de 60 dias, os tratamentos T2, T8 e T9 foram similares, supondo que a adubação química e calagem contribuíram nesse processo (TUCCl et al., 2010); o T3 tendo a maior valor de altura não se assimilou com nenhum dos outros, sendo também influenciado pelo calcário (SATO, 2018). Análises semelhantes foram obtidas por Elacher et al. (2014) num estudo ao observarem o uso do caroço de açaí triturado na formulação de substrato para a produção de mudas de hortaliças brássicas.

Tabela 1: Avaliação semanal da altura das mudas em $\mathrm{cm}$.

\begin{tabular}{|c|c|c|c|c|c|c|c|c|}
\hline TRAT. & 7 dias & 14 dias & 21 dias & 28 dias & 35 dias & 42 dias & 49 dias & 56 dias \\
\hline T1 & $14,7 \mathrm{cG}$ & $15,8 \mathrm{dF}$ & $17,32 \mathrm{deE}$ & $20 c D$ & $20,4 c C D$ & $21,3 c C$ & $21,57 \mathrm{dBC}$ & $22,3 c A$ \\
\hline T2 & $16,1 \mathrm{abF}$ & $17,15 b E$ & $18,05 \mathrm{bcD}$ & $21 b c$ & $21,22 \mathrm{bBC}$ & $22,05 b B$ & $22,42 \mathrm{bcB}$ & $23,4 \mathrm{bA}$ \\
\hline T3 & $16,9 a G$ & $19,1 \mathrm{aF}$ & $19,9 a \mathrm{E}$ & $22,45 a \mathrm{D}$ & $23,375 \mathrm{aC}$ & $23,9 a B C$ & $24,4 a B$ & $25,37 a A$ \\
\hline T4 & $13,17 d D$ & $13,47 e \mathrm{D}$ & $14,25 f C$ & $14,6 \mathrm{gBC}$ & $14,75 \mathrm{gB}$ & $15,02 \mathrm{fB}$ & $14,67 \mathrm{gBC}$ & $15,6 f A$ \\
\hline T7 & $15,77 \mathrm{bH}$ & $16,45 \mathrm{bcdG}$ & $17,4 \mathrm{dF}$ & 18,07efE & $18,72 \mathrm{efD}$ & $19,35 \mathrm{eC}$ & $20,3 e B$ & $21,3 \mathrm{dA}$ \\
\hline T8 & $16,17 \mathrm{abG}$ & $16,55 \mathrm{bcG}$ & $18,37 \mathrm{bF}$ & $19,37 \mathrm{dE}$ & $20,5 c D$ & $21,27 c C$ & $22,97 \mathrm{bB}$ & $24,07 \mathrm{bA}$ \\
\hline T9 & $15,57 \mathrm{bH}$ & $16,6 \mathrm{bcG}$ & $17,32 \mathrm{deF}$ & $18,3 \mathrm{eE}$ & $19,3 \mathrm{dC}$ & $21,1 \mathrm{cC}$ & $22,17 \mathrm{CAB}$ & $23,45 b A$ \\
\hline T10 & $15,57 \mathrm{bG}$ & $16,87 \mathrm{bcF}$ & $17,72 \mathrm{cdE}$ & $18,15 \mathrm{efE}$ & $19,07 \mathrm{deD}$ & $19,87 \mathrm{dC}$ & $21,05 \mathrm{~dB}$ & $22,62 \mathrm{cA}$ \\
\hline
\end{tabular}

*Médias seguidas de letras iguais maiúsculas na mesma coluna (para cada tratamento) não diferem entre si ao nível de $5 \%$ de significância pelo teste $t$ de Student. Médias seguidas de letras iguais minúsculas na mesma linha (para diferentes tratamentos) não diferem entre si ao nível de 5\% de significância pelo teste t de Student. TRAT. = Tratamento.

Em relação a varável diâmetro do coleto, nota-se uma margem significativa de valores entre os tratamentos (Tabela 2). O tratamento T1 apresentou a menor média com o valor de 3,38mm, enquanto o T8 obteve a maior com 3,95mm; O resultado de T8 mostrou-se favorável pois deve-se em virtude a adubação química aplicada no componente (MATOS et al., 2009); ele não se assemelhou a qualquer outro tratamento no final do experimento. 
Resultados semelhantes foram encontrados por Maranho et al. (2012), que ao analisarem o desenvolvimento de mudas de Paricá em produtos compostos por resíduo de açaí ( $0 \%, 25 \%, 50 \%, 75 \%, 100 \%)$ agregados à terra de mata, perceberam que a maioria das médias de diâmetros foram equivalentes a tendência de desenvolvimento da altura, o que já justifica os valores obtidos por T8.

Ainda sobre o estudo de Maranho et al. (2012), estes avaliaram que ao longo de 30 dias, o tratamento de 100\% resíduo de açaí (RA) tivera diâmetro maior comparado aos restantes até a finalização do estudo. Também, notara-se que os valores de açaí a 75\% mostraram-se favoráveis ao cultivo, tendo valores semelhantes aos de 100\% RA. Portanto, justifica-se que mesmo com proporções altas de RA, há possibilidade de cultivo assim como encontrados no T8 (Tabela 2).

Tabela 2: Avaliação semanal do diâmetro do coleto das mudas em mm.

\begin{tabular}{lllllllll}
\hline TRAT. & 7 dias & 14 dias & 21 dias & 28 dias & 35 dias & 42 dias & 49 dias & 56 dias \\
\hline T1 & 3,25bcAB & $3,33 \mathrm{abAB}$ & $3,35 \mathrm{cAB}$ & $3,46 \mathrm{cA}$ & $3,47 \mathrm{bA}$ & $3,07 \mathrm{~dB}$ & $3,22 \mathrm{cAB}$ & $3,38 \mathrm{dAB}$ \\
T2 & $3,36 \mathrm{abD}$ & $3,53 \mathrm{abABCD}$ & $3,56 \mathrm{bABC}$ & $3,58 \mathrm{bAB}$ & $3,69 \mathrm{aA}$ & $3,37 \mathrm{bcCD}$ & $3,41 \mathrm{bcBCD}$ & $3,58 \mathrm{bcAB}$ \\
T3 & $3,71 \mathrm{aAB}$ & $3,78 \mathrm{aAB}$ & $3,81 \mathrm{aAB}$ & $3,82 \mathrm{aAB}$ & $3,89 \mathrm{aA}$ & $3,58 \mathrm{aB}$ & $3,53 \mathrm{abB}$ & $3,69 \mathrm{bAB}$ \\
T4 & $2,69 \mathrm{dE}$ & $3,03 \mathrm{cD}$ & $3,27 \mathrm{cdC}$ & $3,32 \mathrm{dBC}$ & $3,42 \mathrm{bcBC}$ & $3,35 \mathrm{bcBC}$ & $3,47 \mathrm{abB}$ & $3,64 \mathrm{bA}$ \\
T7 & $2,69 \mathrm{dE}$ & $2,92 \mathrm{cD}$ & $3,08 \mathrm{eCD}$ & $3,18 \mathrm{eBC}$ & $3,25 \mathrm{cdABC}$ & $3,33 \mathrm{bcAB}$ & $3,23 \mathrm{cABC}$ & $3,46 \mathrm{cdA}$ \\
T8 & $2,81 \mathrm{dG}$ & $3 \mathrm{cF}$ & $3,07 \mathrm{eEF}$ & $3,17 \mathrm{eDE}$ & $3,25 \mathrm{cdD}$ & $3,40 \mathrm{bcC}$ & $3,65 \mathrm{aB}$ & $3,95 \mathrm{aA}$ \\
T9 & $2,73 \mathrm{dF}$ & $2,88 \mathrm{cEF}$ & $3,01 \mathrm{eDE}$ & $3,15 \mathrm{eCD}$ & $3,3 \mathrm{bcdBC}$ & $3,27 \mathrm{AcBC}$ & $3,39 \mathrm{bcB}$ & $3,67 \mathrm{bA}$ \\
T10 & $2,81 \mathrm{dF}$ & 3cE & $3,12 \mathrm{deD}$ & $3,24 \mathrm{deC}$ & $3,18 \mathrm{dCD}$ & $3,27 \mathrm{AcBC}$ & $3,37 \mathrm{bcB}$ & $3,57 \mathrm{bcA}$ \\
\hline
\end{tabular}

*Médias seguidas de letras iguais maiúsculas na mesma coluna (para cada tratamento) não diferem entre si ao nível de $5 \%$ de significância pelo teste $t$ de Student. Médias seguidas de letras iguais minúsculas na mesma linha (para diferentes tratamentos) não diferem entre si ao nível de $5 \%$ de significância pelo teste t de Student. TRAT. = Tratamento.

Verificando a produção de matéria seca da parte aérea e das raízes do vegetal (Tabela 3), T8 obteve a maior média, contendo $75 \%$ caroço de açaí triturado e $25 \%$ solo com adubação química com valores de 0,76 e 2,32, respectivamente. Isso pode ser em virtude de seus atributos altura e diâmetro do coleto estarem elevados, o que dispõe de maior quantidade de matéria a ser gerada. Estatisticamente, ele se diferenciara $100 \%$ aos demais tratamentos tanto na sua parte aérea quanto na radicular.

Quanto às menores médias encontradas de MSPA, T1 apresentou valor de 0,51g, e a MSR pelo T4 com 1,38g (Tabela 3). O primeiro é justificado como menor, tendo em vista o solo sem nenhum tipo de tratamento específico. Já o segundo contendo $50 \%$ açaí triturado e $50 \%$ solo pode ter seu crescimento radicular reduzido em razão da carência de adubação química ou calagem para melhorar seu desempenho. A MSPA do T1 não se assemelhou estatisticamente com qualquer outro tratamento, assim como o T4 não se igualou aos demais na MSR.

Portanto, toma-se que a fabricação de massa seca é uma variável que detém grande importância na verificação dos desempenhos de vegetais de acordo com os inúmeros fatores externos que eles são submetidos, tal qual o substrato (MARANHO et al., 2012). Assim, a capacidade das plantas na absorção de água e captura de nutrientes presentes no solo com um crescimento radicular mais desenvolvido é propício às espécies para o melhor funcionamento de suas ações no ecossistema (TAIZ et al., 2009).

No Índice de Qualidade de Dickson, tendo como referência o valor sugerido por Hunt (1990), todas as mudas apresentaram índices para o plantio considerados ótimos (Tabela 4), sem tratamento abaixo de 0,20. De modo geral, os índices variaram de 0,22 a 0,33 em 60 dias, estando todos de acordo com a proposta 
de Hunt (1990) e aptos a serem aplicados a novos testes. Os tratamentos de maior e menor índice ao longo do experimento foram T8 e T1.

Tabela 3: Matéria seca da parte aérea, raiz e total das mudas.

\begin{tabular}{lllllllll}
\hline & T1 & T2 & T3 & T4 & T7 & T8 & T9 & T10 \\
\hline MSPA (g.planta-1) & $0,51 \mathrm{e}$ & $0,62 \mathrm{c}$ & $0,72 \mathrm{~b}$ & $0,57 \mathrm{~d}$ & $0,71 \mathrm{~b}$ & $0,76 \mathrm{a}$ & $0,71 \mathrm{~b}$ & $0,62 \mathrm{c}$ \\
MSR (g.planta $^{-1}$ ) & $1,78 \mathrm{bc}$ & $1,71 \mathrm{c}$ & $1,78 \mathrm{bc}$ & $1,38 \mathrm{f}$ & $1,53 \mathrm{e}$ & $2,32 \mathrm{a}$ & $1,80 \mathrm{~b}$ & $1,63 \mathrm{~d}$ \\
MST (g.planta- $^{-1}$ ) & 2,3 & 2,34 & 2,5 & 1,96 & 2,24 & 3,09 & 2,52 & 2,25 \\
\hline
\end{tabular}

*Médias seguidas de letras iguais minúsculas na mesma linha não diferem entre si ao nível de $5 \%$ de significância pelo teste $t$ de Student.

Tabela 4: Avaliação do Índice de Qualidade de Dickson.

\begin{tabular}{llllllll}
\hline & \multicolumn{1}{c}{} & IQD & & & \\
\hline T1 & T2 & T3 & T4 & T7 & T8 & T9 & T10 \\
0,22 & 0,25 & 0,26 & 0,29 & 0,27 & 0,33 & 0,28 & 0,25 \\
\hline
\end{tabular}

Na avaliação da área foliar (Tabela 5), houve variação significativa entre os tratamentos. A menor média encontrada nesta variável foi o T4 com $51,74 \mathrm{~cm}^{2}$, enquanto a maior média da área foliar descrita foi $111,25 \mathrm{~cm}^{2}$ pelo $\mathrm{T} 8$, com $75 \%$ açaí triturado e $25 \%$ solo.

Isso está refletido diretamente ao número de folhas encontrados ao fim do experimento, onde T8 possuía 5 folhas; em T4 apenas 2 folhas foram desenvolvidas. Frigotto et al. (2015) afirma que quanto maior a parcela de área foliar na espécie, melhor será a obtenção de outros nutrientes pela ação da fotossíntese.

Vale destacar que o T10 foi o único tratamento que se assemelhou estatisticamente com todos os demais, dando subsídios para melhores pesquisas a respeito do uso total de caroço de açaí na composição de substrato em cultivos de espécies com intuito de reflorestamento ou recuperação de áreas degradas.

Tabela 5: Avaliação da área foliar em $\mathrm{cm}^{2}$.

\begin{tabular}{llllllll}
\hline \multicolumn{7}{c}{ Área Foliar } \\
\hline T1 & T2 & T3 & T4 & T7 & T8 & T9 & T10 \\
$68,62 \mathrm{bc}$ & $65,28 \mathrm{bc}$ & $72,19 \mathrm{bc}$ & $51,74 \mathrm{c}$ & $90,45 \mathrm{ab}$ & $111,25 \mathrm{a}$ & $65,37 \mathrm{bc}$ & $84,24 \mathrm{abc}$ \\
\hline
\end{tabular}

*Médias seguidas de letras iguais minúsculas na mesma coluna não diferem entre si ao nível de $5 \%$ de significância pelo teste $t$ de Student.

Assim sendo, tem-se a matriz de correlação de Pearson (Tabela 6) que expressou uma correlação significativa e positiva entre a massa seca da raiz e a massa seca total com a altura da parte aérea $\left(0,68^{*}\right.$ e 0,69*). A parte aérea tem papel fundamental na propagação de dióxido de carbono (CO2) e vapor d'água (H2O) nos estômatos, a fim de atribuir melhor desempenho na planta (SMITH, 2006). Portanto, quanto maior o acúmulo de matéria seca, melhor será a ocorrência das trocas gasosas entre as organelas do vegetal e a zona atmosférica, facilitando processos importantes como a fotossíntese (CRUZ, 2018).

Houve correlação significativa e positiva entre a massa seca da parte aérea, massa seca total e Índice de Qualidade Dickson com o diâmetro do coleto $\left(0,68^{*}, 0,70^{*}\right.$ e $\left.0,86^{*}\right)$ (Tabela 6). Conforme o estudo realizado por Frigotto et al. (2015), as plantas têm a necessidade de obter um diâmetro de coleto mínimo, para que se possa manter o sustento da espécie, influenciando diretamente no melhor desenvolvimento para obtenção de nutrientes.

No que se refere ao Índice de Qualidade de Dickson, obteve-se correlação significativa entre as variáveis DC e MSPA (0,86* e 0,68*) (Tabela 6). As análises realizadas por Eloy et al. (2013) em espécies do 
gênero Eucalyptus aplicadas a substratos distintos também tiveram a constatação similar ao encontrar correlação positiva nestes quesitos.

Tabela 6: Coeficientes de correlação de Pearson entre as variáveis do experimento.

\begin{tabular}{|c|c|c|c|c|c|c|c|}
\hline & APA & DC & $\mathbf{A F}$ & MSPA & MSR & MST & IQD \\
\hline APA & 1 & & & & & & \\
\hline DP & 0,19 & 1 & & & & & \\
\hline AF & 0,5 & 0,34 & 1 & & & & \\
\hline MSPA & 0,43 & $0,68 *$ & 0,46 & 1 & & & \\
\hline MSR & $0,68^{*}$ & 0,61 & $0,70^{*}$ & $0,43^{*}$ & 1 & & \\
\hline MST & $0,69^{*}$ & $0,70^{*}$ & $0,71 *$ & 0,63 & $0,97^{*}$ & 1 & \\
\hline IQD & 0,15 & $0,86^{*}$ & 0,33 & $0,68^{*}$ & 0,37 & 0,51 & 1 \\
\hline
\end{tabular}

*Significativo ao nível de $5 \%$ de probabilidade $(\mathrm{p}<0,05)$ pelo teste t. Variáveis: Altura da parte área (APA), Diâmetro do coleto (DC), Área foliar (AF), Massa seca da parte aérea (MSPA), Massa seca da raiz (MSR), Massa seca total (MST) e Índice de qualidade de Dickson (IQD).

\section{CONCLUSÕES}

Observou-se que o tratamento T8 (75\% açaí triturado e $25 \%$ solo com adubação química) proporcionou bons resultados entre os parâmetros avaliados, sendo os valores de altura, diâmetro do coleto MSPA, MSR, MST e área foliar de 24,07cm, 3,95mm, 0,76g, 2,32g, 3,09g e 111,25cm2, respectivamente. Sendo o uso do caroço de açaí triturado como substrato de mudas, uma boa alternativa para destinação final do resíduo.

Ainda que o T10 (100\% Caroço de açaí triturado) não tenha os melhores parâmetros, este serve como base a estudos que possuam o intuito de reutilizar estes insumos, pois os resultados obtidos também foram satisfatórios a possíveis cultivos de espécies florestais na recuperação de áreas degradadas.

\section{REFERÊNCIAS}

BARROS, D. L.. Caracterização e utilização de biocarvão proveniente de resíduo madeireiro na produção de mudas florestal, frutífera e a campo de Teca (Tectona grandis L.f.). Tese (Doutorado em Agronomia) - Universidade Federal de Lavras, Lavras, 2017.

BICAS, T. C.. Valorização de subprodutos agroindustriais: potencial utilização em indústrias alimentícias e de biotecnologia. Monografia (Bacharelado em Química) Universidade Tecnológica Federal do Paraná, Pato Branco, 2016.

BRASIL. Lei n. 12.305 de 2 de agosto de 2010. Institui a Política Nacional de Resíduos Sólidos; altera a Lei no 9.605 de 12 de fevereiro de 1998; e dá outras providências. Brasília: DOU, 2010.

CARVALHO, M. C. S.; NASCENTE, A. S.; BARBOSA, G. F.; MUTADIUA, C. A. P.; DENARDIN, J. E.. Época de semeadura afetando o desenvolvimento de cultivares de feijão em Lichinga, província de Niassa, Moçambique. Rev. Ceres, v.64, n.5, p.532-539, 2017. DOI: http://dx.doi.org/10.1590/0034737x201764050011

CRUZ, T. S.. Divergência fenotípica em variedades do gênero schizolobium por caracteres biométricos e fisiológicos. Dissertação (Mestrado) - Universidade Federal do Recôncavo da Bahia, Cruz das Almas, 2018.
DICKSON, A.; LEAF, A. L.; HOSNER, J. F.. Quality appraisal of white spruce and white pine seedling stock in nurseries. Forest Chronicle, v.36, p.10-13, 1960. DOI: https://doi.org/10.5558/tfc36010-1

ELACHER, W. A.; OLIVEIRA, F. L.; SILVA, D. M. N.; QUARESMA, M. A. L.; CHRISTO, B. F.. Caroço De Açaí Triturado Fresco Na Formulação De Substrato Para A Produção De Mudas De Hortaliças Brássicas. Enciclopédia Biosfera, Goiânia, v.10, n.18, p.2930-2940, 2014.

ELOY, E.; CARON, B. O.; TREVISAN, R.; SCHMIDT, D.; ZANON, M. L. B.; BEHLING, A.; MONTEIRO, G. C.. Avaliação da Qualidade de Mudas de Eucalyptus Grandis Utilizando Parâmetros Morfológicos. Floresta, v.43, n.3, p.373-384, 2013. DOI: http://dx.doi.org/10.5380/rf.v43i3.26809

FEIO, V. F.; GIRARD, L.; MENDONÇA, N.. Problemática da geração de efluentes oriundos do processamento de açaí na região metropolitana de Belém-PA. Revista Monografias Ambientais, v.13, n.3, p.3335-3340, 2014. DOI: https://doi.org/10.5902/2236130813370

FERREIRA-LEITÃO, V.; GOTTSCHALK, L. M. F.; FERRARA, M. A.; NEPOMUCENO, A. L.; MOLINARI, H. B. C.; BOM, E. P. S.. Biomass residues in Brazil: availability and potential uses. 
Waste and Biomass Valorization, New York, v.1, p.65-76, 2010. DOI: http://doi.org/10.1007/s12649-010-9008-8

FRIGOTTO, T.; BRUN, E. J.; MEZZALIRA, C. C.; NAVROSKI, M. C.; BIZ, S.; RIBEIRO, R. R.. Desenvolvimento de mudas de Schizolobium amazonicum Huber ex Ducke em diferentes ambientes em viveiro1. ENFLO Ecologia e Nutrição Florestal, v.3, n.1, 2015 .

HUNT, G. A.. Effect of styroblock design and cooper treatment on morphology of conifer seedlings. In: ROSE, R.; CAMPBELL, S. J.; LANDIS, T. D.. Target seedling symposium, meeting of the western forest nursery associations, general technichal report RM-200. Roseburg: Proceedings Collins: United States Departament of Agriculture, Forest Service, 1990. p.218-222.

KRZYZANOWSKI, F. C.; FRANÇA-NETO, J. B.; HENNING, A. A.. Relato dos testes de vigor disponíveis para as grandes culturas. Embrapa Soja-Artigo em periódico indexado, 1991

MARANHO, Á. S.; PAIVA, A. V.. Produção de mudas de Physocalymma scaberrimum em substratos compostos por diferentes porcentagens de resíduo orgânico de açaí. Floresta, v.42, n.2, p.399-408, 2012. DOI: http://dx.doi.org/10.5380/rf.v42i2.19220

MATOS, G. D.; FRIGOTTO, T.; MARTINS, A. P. M.; BRUN, E. J. Desenvolvimento de mudas de paricá (schizolobium amazonicum huber ex ducke) em substrato orgânico: estudo de caso. Synergismus Scyentifica UTFPR, Pato Branco, v.04, n.1, 2009.

NEVES, G.; DALCHIAVON, F. C.; CARGNIN-STIELER, M.. Superação da dormência em sementes de Schizolobium amazonicum. UNICiências, v.14, n.2, 2010. DOI: https://doi.org/10.17921/1415-5141.2010v14n2p\%25p

ROSA, M. F.; SOUZA FILHO, M S. M.; FIGUEIREDO, M. C. B.; MORAIS, J. P. S.; SANTAELLA, S. T.; LEITÃO, R. C.. Valorização de resíduos da agroindústria. In: SIMPÓSIO INTERNACIONAL SOBRE GERENCIAMENTO DE RESÍDUOS AGROPECUÁRIOS E AGROINDUSTRIAIS, 2. Anais. Foz do Iguaçu, 2011. p.98-105.
SATO, M. K.. Biocarvão de resíduos de açaí como condicionante de solos. Tese (Doutorado em Agronomia) Universidade Federal Rural da Amazônia, Belém, 2018.

SHIMIZU, E. S. C.; PINHEIRO, H. A.; COSTA, M. A.; SANTOS FILHO, B. G.. Aspectos fisiológicos da germinação e da qualidade de plântulas de Schizolobium amazonicum em resposta à escarificação das sementes em lixa e água quente. Revista Árvore, v.35, n.4, p.791-800, 2011. DOI: http://dx.doi.org/10.1590/S0100-67622011000500004

SOUSA, A. A. T. C.. Biochar de lodo de esgoto: efeitos no solo e na planta no cultivo de rabanete. Dissertação (Mestrado em Agronomia) - Universidade de Brasília, Brasília, 2015.

PADUA, G. P.; ZITO, R. K.; ARANTES, N. E.; NETO, F. Influência do tamanho da semente na qualidade fisiológica e na produtividade da cultura da soja. Embrapa Soja-Artigo em periódico indexado (ALICE), 2010.

PÁDUA, T. R. P.; SILVA, C. A.; DIAS, B. O.. Nutrição e crescimento do algodoeiro em Latossolo sob 1481 diferentes coberturas vegetais e manejo de calagem. Ciênc. Agrotec., Lavras, v.32, n.5, p.1481-1490, 2008. DOI: http://dx.doi.org/10.1590/S1413-70542008000500019

TAIZ, L.; ZEIGER, E.. Fisiologia vegetal. 4 ed. Porto Alegre: Artmed, 2009.

TEIXEIRA, L. B.; OLIVEIRA, R. F.; FURLAN JUNIOR, J.; CRUZ, E. S.; GERMANO, V. L. C.. Processo de compostagem a partir de lixo orgânico urbano e caroço de açaí. Circular Técnica, N. 105. Belém: Embrapa Amazônia Oriental, 2004.

TUCCI, C. A. F.; LIMA, H. N.; GAMA, A. S.; COSTA, H. S.; SOUZA, P. A.. Efeitos de doses crescentes de calcário em solo Latossolo Amarelo na produção de mudas de pau-de-balsa (Ochroma lagopus sw., bombacaceae). Acta Amaz., Manaus, v.40, n.3, 2010. DOI: http://dx.doi.org/10.1590/S0044-59672010000300013

A CBPC - Companhia Brasileira de Produção Científica (CNPJ: 11.221.422/0001-03) detém os direitos materiais desta publicação. Os direitos referem-se à publicação do trabalho em qualquer parte do mundo, incluindo os direitos às renovaç̃ões, expansões e disseminações da contribuiç̃o, bem como outros direitos subsidiários. Todos os trabalhos publicados eletronicamente poderão posteriormente ser publicados em coletâneas impressas sob coordenação da Sustenere Publishing, da Companhia Brasileira de Produção Científica e seus parceiros autorizados. Os (as) autores (as) preservam os direitos autorais, mas não têm permissão para a publicação da contribuição em outro meio, impresso ou digital, em português ou em tradução. 